arguments against consolidated balance sheets and earnings statements increasingly lose validity as more important and ramified groups publish these documents, and it might well have been hoped that the president would have permitted himsclf the expression of somewhat more advanced views than those of the Greene Committee in 1926.

\section{WETENSCHAPPELIJKE BEDRIJFSLEIDING EN DETAILHANDEL}

$O_{\text {p }}$ viijwel alle gebieden van menschelijk kemnen en kunnen is men geliomen tot methodisch handelen. Men werkt niet meer incidenteel, laat zich niet meer door de omstandigheden leiden, maar tracht van te voren opgestelde plammen te volvoeren. Het eerste gebied, warop deze methode ran denken en handelen consequent werd toegepast, was dat der natuurwetenschappen. Men trachtte de wetten op te sporcn, die de natuurverschijnselen behecrschten on daarna zelf tot kennis en beheersching der natuur te komen. De kolossale vlucht, welke de industrie in dit zelfde tijdvak nam, is hier een rechtstreekseh gevolg van. Met Taylor, Fayol c.s. deden diezelfde wetensehappclijke methoden in de industrie zelve hun intrede. I)iepgaand zijn de verschillende fabricatieprocessen onderzocht en geanalyseerd. De gevolgen bleven nict uit, een stceds grooter stroom van steeds goedkooper producten werd over onze wereld uitgestort.

En tocn openbaarde zich een spanning tusschen de industrie en den handel. De handel was nog niet wetenschappelijk ,door georganiseerd'. Hij zal dit voorloopig nog wel niet worden ook, de overgroote meerderheid van de klemhandelbedrijven is van te ger'ingen onvang, om er een wat dieper gaande wetenschappelijk opgezette organisatic met v'ucht te kunnen instellen.

Toch is het zeer zeker leerzaam en interessant eens na te gaan, welke methoden van wetenschappelijke bedrijfsleiding alzoo aanbevolen worden en in welke mate deze suces kunnen hebben. Uit den aard der zaak moet ik hier wel zeer onvolledig zijn en beperk ik mij tot het aangeven van een aantal richtlijnen.

De bekende Duitsche Hooglecraar Prof. 1)r. J. Hirsch is vooral een warm roorstancler van de uitwisseling van $z . g$. kentallen, een methode, welke ook in de industrie niet onbekend is. Op een aantal kenmerkende verschillen tusschen industrie en handel moet hier evenwel madrukkelijk gewezen worden.

In de industrie cen samenwerken van mensehen en machines tot het bereiken van een bepaald doel. In den handel heeft men virjwel uitsluitend met menschen te maken. Dit onderscheid is uiterst belangrijk. In het fabrieksbedrijjf komt men tot anders geaarde kentallen dan in den handel. De industrie kent een auntal kentallen, waarin de menschelijke factor vrijwel geen rol spcelt, waarbij hij althans niet in teller of noemer voorkomt. B.v. kentallen, welke op machine-prestaties, krachtverbruik e. d. betrekking hebben. Voorts is van cen bepaalde fabrick of fabrieksafdeeling de mogelijke prestatie vaak zéér nauwkcurig te berekenen. Een autofabriek kan b.v. 100 wagens per dag afleveren. Dat een productie van 80, 110 en 90 anto's overeenstemt met een belasting van resp . 80,110 en $90 \%$ is reeds bij voorbat buiten discussie.

Bij den handel datentegen zijn de ,niet-menschelijke" kentallen zéér gering in aantal. Daarenhoven missen zij de absoluutheid der industriciele kentallen in hooge mate. Wamneer is b.v. een winkelbedrijf vol bclast en hoc is de mate van belasting in cen kental uit te drukken?

De fabrielsmachines zijn het, die aan de industriëele kentallen een zelier houvast geven. Zij dwingen een zekere werkwijze op en bevorderen daardoor in hooge mate de vergelijkbaarheid van de prestatic der versehillende bedrijven. De handel mist dat alles en wanneer men hier kentallen op gaat stellen, dient mon dat met de uiterste roorzichtigheid te doen.

In den kleinhandel richt alles zich, vooral op den omzet. Bijna elk kental houdt daamee verband. Van de onkosten maken voor'al de personeelkosten een hoog percentage uit. „Omzet per hoofd" is dus een kental, dat zich direct aan ons opdringt. Maar wat denken wij met een dergelijk kental feitelijk te bcreiken?

Nemen wij, als concreet voorbeeld, de massa-filiaalonderneming. Wat leert dat cijfer ons dan, wammeer wij eenige bedrijven met elkaal' gaan vergelijken?

Van de efficiency van den winkel niets, immers, behalve bij den directen verkoop zijn er nog velen bij beheer, inkoop, administratic, expeditie, controle en zoo al meer werkzaam. Waar al dergolijke ondernemingen on elk weer in een andere mate, aan zelf-fabricatie, verpalkking van bepaalde artikclen e.d. doen, worden hiermee zooveel uiteenloopende gegevens in het kental verwerkt, dat het voor de bepaling van de efficiency van het winkelpersoneel weinig zin meer heeft.

Nemen wij daarentegen den onzet per winkelbediende, dan geeft ons dat al evenmin houvast. In de eerste plaats verschilt de personeelpolitiek bij de verschillende concerns aanzienlijk. Ien kan de verkoopsleiding b.v. viijwel geheel aan kantoor trekken, waarmee tevens een uitgebreid apparaat van controleurs en districtsleider's wordt ingeschakeld, maar het winkelpersoncel ontlast. Men kan nog verder gaan en viijwel de geheele winkelleiding, b.v. toezicht op de voorraden naar kantoor toe brengen, wat een aanzienlijke uitbreiding van de personeelbezetting van de statistiekafdeeling ten gevolge heeft, maar het winkelpersoneel wederom ontlast. In aldus geleide zaken is een gunstig eijfer voor den omzet per winkelbediende waarschijnlijk; houdt men evenwel rekening met de extra werkkrachten, welke deze methode elders vergt, dan kan zij wel eens in een nadeel omslaan. Bovendicn, ons interesseert niet alleen de omzet per hoofd, maar toch zeker evenzecl de omzet per betaalde loonecnheid. En de loonen van controleurs en distrietsleider's zijn vrij wat hooger, dan die welke aan het winkelpersoneel uitbetaald worden. Hierbij komt nog de zeer amzienlijke onkosten (reis-, verblijf e.d.) welke dergelijke functionarissen met zich brengen. Lin deze kosten worden uit den aard der zaak niet op de loonen geboekt!

Een tweede zeer belangrijk kental is de omzetsnelheid der voorraden. $\mathrm{Bij}$ berekening hiervan worden nogal eens fouten gemaakt, waarvoor ik hier terloops wil waarschuwen. De verkoop berekent men allicht tegen verkoopswarde. De voorraden daarentegen worden bij roorkeur opgenomen wanneer zij klein zijn en voor balansdoeleinden laag gewaardeerd. Men krijgt zoo omzetcijfers, welke veel te hoog zijn. Deze fout wordt zelfs in belangrijke bedrijven gemaakt. Uit mijn eigen ervaring heb ik b.v. het geval van een vij aanzienlijke I) uitsche cenhcidsprijzenonderneming. Op grond der mij verstrekte gegevens zouden de voorraden hier eirea 8 maal per jaar worden ongezet. Van bepaalde afdeelingen werden mij eveneens de eijfers verstrekt. Een eenvoudige berekening leerde mij toen, dat de omzet in eenige andere afdeelingen dan welhaast met fantastische snelheid (250 mal per jaar!!) moest plats hebben. Bij nauwkeurige analyse bleken de cijfers dan ook heel ander's te liggen. Dat alcius verkregen cijfers alleen maar onheil kunnen stichten, behoeft hier niet betoogd te worden. Zijn ze goed opgesteld, dan kummen zij hoogst waardevol zijn. Wị beschikken hier over ,niet menschelijke" kentallen, dic bovendien reeds zonder vergelijking met andere bedrijven boekdeelen kunnen spreken. Een bestudeering van de omzetsnelheden der verkochte artikelen zal allicht aanleiding tot herziening van het assortiment geven. 
Zooals ik reeds opmerkte, gaan de meeste kentallen van den omzet uit. Mijn bezwaar hiertegen is, dat het doel van een handelsbedrijf niet is het halen van omzet, eenigszins stoutmoedig zou ik bijna het tegendeel durven beweren! Want in bijna alle landelsbedrijven valt een sterke stijging der onkosten met het stijgen van den omzet waar te nemen. Ten slotte gaat het om let behalen van winst. En de maximale winst valt maar zeer zelden met den maximalen omzet samen. En juist in dit opzicht vertellen ons de verschillende kentallen maar bitter weinig. Fen betere methode zie ik daarom in de volgende wijze van handelen.

Men dient daarbij uit te gaan van het gevocrde warenassoltiment. Dit is op verschillende wijzen in te deelen, b.v. naar bij elkaar hoorende artikelengroepen. In een kruideniersbedrịf vormen b.v. koffie- en thee, zuidvruchten, peulvruchten dergelijke afdeelingen.

Een andere indecling is naar bruto winst percentages. Een bezwaar hierbij, is dat deze niet constant zijn.

Eveneens interessant is een indeeling in :

1. Concurrentie-artikelen, dus artikelen, welke men met geen of met een kleine winstmarge moet verkoopen.

2. Artikelen, welke men on prestige-redenon, ter afronding van het assortiment en dergelijke overwegingen meent te moeten voeren. Eventucel zouden zij onder groep 1 kunnen worden ondergebracht.

3. Artikelen met vasten verkoopprijs. B.v. merkartikelen. Hiermee is concurreeren onmogelijk, terwijl de winstmarge min of meer door derden wordt opgedrongen.

4. De ,normale" artikelen, waarbij men vrij is in de prijsbepaling en welke niet door" de concurrentie, ,verknoeid" zijn.

Het spreekt van zelf, dat de sterke onderneming er vooral op uit zal zijn zooveel mogelijk alleen de onder 4 genoemde waren te voeren. Maar ook voor de minder krachtige verdient het aanbeveling de groepen 1 en 2 ter dege te observeeren.

Natuurlijk is ook een indeeling volgens een combinatie van verschillende hierboven genoemde gezichtspunten mogelijk. Meestal zal het bovendien nog wensehclijk zijn, bepaalde hoofdartikelen of nieuw ingevoerde waren speciale aandacht te schenken.

Hiernaast tracht men de onderneming zoo zuiver mogelijk in bepaalde onderafdeelingen als beheer, verkoop, inkoop, magazijn, expeditie en controle te splitsen. De verschillende in de onderneming gemakkte kosten worden zoo zuiver mogelijk over de verschillende afdeelingen verdeeld.

Het docl van de onderneming is met behulp van deze afdeelingen de verschillende warengrocpen zoo winstgevend mogelijk te verkoopen. Daarom is nu de volgende stap een toewijzen van de in die afdeelingen gemaakte kosten aan de verschillende warengroepen.

Fen en ander kan tot verschillende complicaties maar ook tot verdere gevolgtrekkingen aanleiding geven. Even bonieuwd als men is naar het rendement van bepaalde warengroepen is men ook naar dat van de verschillende winkels. Wil men dit berekenen, dan zal men eveneens de verschillende hiervoor genoemde afdeclingskosten over de winkels moeten omrekenen of moeten omslaan en ook hier duiken dan weer moeilijkheden op.

B.v. hoe met de transportkosten te doen?

Hen filiaal, dat in dezelfde plaats gevestigd is als de voor. raadmagazijnen zal allicht lagere transportkosten hebben dan een, dat op een $200 \mathrm{k} . \mathrm{m}$. afstand gelegen is. Voor het rendement van het filiaal zelf is het natuurlijk zuiver en gewenscht, dat in het cene geval de transportkosten tegen een lager bedrag op- gevoerd worden dan in het andere. ${ }^{1}$ ). Maar wanneer men het beleid in de winkels zclf aan de hand van dergelijke cijfers wil gaan bestudeeren en de behaalde resultaten vergelijken, dan is het toch wel onlogisch den een met een hoogen kostenfactor te belasten, welke geheel buiten zijn schuld veroorzaakt wordt, terwijl de ander, eveneens geheel buiten eigen toedoen, veel fraaicre resultaten mag boeken.

En een weglaten van de transportkosten is hier al evenzeer uit den booze, immers, dan komt niet tot uiting, hoe verschillende filialen geregeld onvoldoende bestellen, waardoor dure nazendingen noodzakelijk worden. Voor het vergelijken der winkelresultaten zal hier dus naar een bepaalden sleutel, b.v. afhankelijk van de waarde der nabestellingen, gezocht moeten worden.

Keeren wij nu weer tot de resultaten-berekening van de verschillende warengroepen terug. Verschillende afdeelingskosten zal men hierover direct kunnen verdeelen, bij andere, b.v. die voor controle, kan een verdeeling via cen andere afdeeling, in het beschouwde geval ,verkoop", makkelijker en beter gebeulen.

Maar ook hier zal de verdeeling verschillende moeilijkheden met zich brengen. B.v. : Hoe zal men de magazijnkosten omslaan? Naar waarde van de artikelen? Maar in een aantal gevallen wordt dit vrijwel steeds direct door den leverancier aan het filiaal geleverd, een ander maal is het weer.een hoogwaardig seizoenartikel, dat dus gedurende korten tijd geringe plaatsruimte in beslag neemt. Fn zoo zij̄n or nog meerdere bedenkingen te noemen. Maar hoe 'n verdeeling men ten slotte ook mag kiezen, een eenvoudig omslaan volgens een bepaalden sleutel is in elk geval uit den booze.

Op deze wijze kan men de verschillende artikelengroepen naar hun resultaten (eventueel per winkel) onderzocken. Aldis komt men tot een diepe kemnis van het bedrijf.

Eveneens is het mogelijk, roor „,inwendig gebruik" verschi] lende kentallen met de hiervoor afgeleide gegevens te combineeren. Men kan b.v. den gemiddelden maandomzet der onder neming, voor: elk der artikelengroepen of voor elken winkel beJekenen en dan nagaan in welke mate clke maand van dat gemiddelde afwijkt. Dergelijke gegevens zijn ook voor de verschillende onkostenbronnen overzichtelijk te groepeeren. Uit den aard der zaak is de grafische voorstelling hiervoor de aange. wezen methode. Doordat de norm, b.v. de gemiddelde maandomzet, een gemiddeld onkostenbedrag per mand bij de voor de hand liggende keuze der coördinaatassen als een horizontale lijn verschịnt, zijn de maandelijksche afwijkingen zonder de minsto moeite direct in geldbedragen of pereentages af te lezen.

Uit dit en dergelijk statistisch materiaal ontwikkelt zich a.h. w. vanzelf een goede ondernemingsplanning. Niet alleen voor zoover het de te voeren artikelen, de grootte van den inkoop voor bepaalde seizoenen, het pousseeren van compensatieartikelen of wat dies meer zij betreft, maar ook voor opening en inrichting van nicuwe filialen. Het zal b.v. blijken, dat vooral bij winkels in bepaalds districten de onkosten boven het gemiddelde blijven en dat dit ook het geval is bij winkels boven of beneden een bepaalde grootte. Harmonisch grocit hieruit een steeds verder gaande ondernemingsplanning.

En is men eenmaal op dit punt aangekomen, dan zal er allicht aanlciding bestaan nogmaals op de idee der kentallen en derzelver uitwisseling terug to komen. De winkelondernemingen hebben dan, wat hun organisatorischen groei betreft, een proces doorloopen, dat met dat van de fabrieksondernemingen te ver.

1). Meestal slaat men de transportkosten volgens een bepaalden sleutel om. Waar deze vaak 1-2 \% der verkoopskosten uitmaken en de nettowinsten per omzet in vele gevallen onder de $1 \%$ liggen is het evident, dat men zoo voor de verafgelegen winkels boekwinsten kan berekenen, terwijl in werkelijkheid de winkel nadeelig is en nadeelig blijven moet. 
gelijken is. En al zal dan nog steeds het bezwaar blijven bestaan, dat de gang van zaken in een winkelonderneming nooit in zoo vergaande mate vast te leggen is als dat mogelijk is bij de fabriek, al blijft ook het in dit opstel buiten beschouwing gelaten probleem van de zeer onregelmatigc helasting, welke den winkel eigen is, toch is er lan van cen uitwisseling van eijfers zeer zeker positief nut te verwachten.

Ir. K. F. MALLEE

\section{DE WERKWIJZE VAN DE BEURSAFDEELING OP EEN GROOTBANK}

Dere afdeeling is belast met het koopen en verkoopen van fondsen op de beurs, zoowel voor rekening van eliënter: als voor eigen rekening. Daar echter alle orders niet den zelfden dag uitgevoerd kumnen worden, is dus een allereerste vercischte een goede order-administratie.

Om ca. 3 uur 's middags is pas in het geheel bekend, welke van de loopende orders zijn uitgevoerd, en dus begint de afrekening aan cliënten eerst om ca. $31 / 2$ of 4 uur. In enkele uren, ca. $2 \frac{1}{2}$ uur, moeten alle uitgevoerde orders verwerkt worden, en wel zoodanig, dat fouten zooveel mogelijk zijn voorkomen.

Daarom is naast de order-administratie een juiste organisatie en werkverdeeling noodig, opdat het werk in zoo'n snel mogelijk tempo verloopt.

Ik wil nu eerst behandelen de Order-administratie.

Van alle binnengekomen orders, zoowel mondelinge, telefo. nische, telegrafische als schriftelijke orders, wordt een orderbriefje in viervoud gemaakt. Dit order-formulier ziet er als volgt uit :

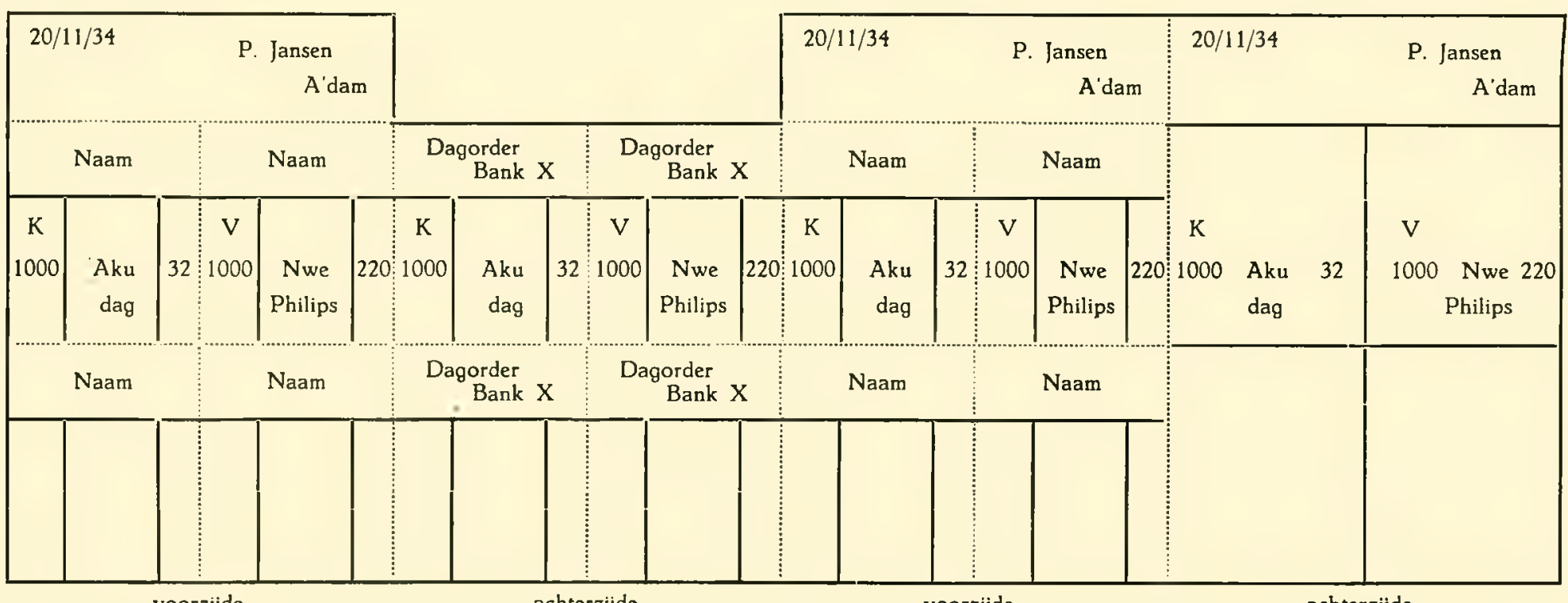

I)it formulier wordt in harmonicavorm opgevouwen, zoodat dan de bedrukte zijden naar boven liggen en men door middel van carbonpapier in één handeling vier gegevens verkrijgt.

Voor icdere cliënt wordt een apart formulier gebruikt en op dat formulier kunnen dus voor één cliënt 4 orders worden genoteerd. Geeft hij slechts 1 order op, dan blijven de overige onbenut en worden na verdere behandeling weggegooid.

We zullen het origincel met de 3 doorslagen in de verdere behandeling noemen : $a, b$, en $d$.

Nadat de orders zijn uitgeschreven, worden deze door een ander vergeleken met de schriftelijke opdracht of het telegram. Daarom maakt men aan de balie van mondelinge orders meestal schriftelijke, door de order op een formulier in enkelvoud te noteeren en dit door den cliënt te laten onderteekenen. Bij telefonische orders wordt volstaan met de orders na opneming door den opnemer te laten herhalen. $\mathrm{Na}$ goedkeuring van den cliënt, wordt het gesprek verbroken.

De orderbriefjes worden nu als volgt gescheiden:

$\mathrm{a}, \mathrm{b}, \mathrm{c}+\mathrm{d}$.

a. dient roor de order-administratie per fonds

b. " " den beursbediende of makelaar/cơmmissionnair"

c. dient voor de order-administratie per cliënt

d. , , dagboek.

\section{BEHANDFLING DER FORMULIEREN.}

Origineel a.

$\mathrm{Na}$ seheiding der 4 doorslagen wordt op a. de naam van den cliënt boven de vier vakjes geschreven (tenminste als alle 4 vakjes een order bevatten). Nadat deze 4 vakjes door perforatie gescheiden zijn, worden deze slips a. per fonds verzameld en door een klem bij elkaar gehouden. De royementen worden dan behandeld.

\section{Doorslag 6 .}

Dit is het briefje voor den beursbediende of makelaar ter beurze. Van order's die gerescontreerd kunnen worden, wordt. dit natuurlijk niet doorgegeven. Doordat doorslag b. geen bovenstrook heeft, is hierop geen naam van den cliënt te zien, welke dus ook niet boven de 4 vakjes gezet kan worden. Deze 4 vakjes worden door perforatie gescheiden, waarna deze slips b. per beursbediende of makelaar worden gesorteerd.

\section{Doorslagen $c+d$.}

Deze blijven voorloopig aan clkaar op kantoor. Nadat de royementen behandeld zijn en dus op c. en d. zijn doorgehaald of van een stempel "geroyeerd" zijn voorzien, worden ze gescheiden, doch blijven, om hierna te noemen reden, op dezelfde volgorde liggen.

Joor de grootbanken worden terwille van een vlugge behandeling der orders, in het beursgebouw één of meer lokalen gehuurd, waar tijdens de beursuren het grootste deel van het personeel der beursafdeeling zit om telefonische gesprekken te voeren, order's direct ter beurze te kunnen uitvoeren enz.

Een deel van de orders wordt aan makelaars en/of commissionnairs ter beurze doorgegeven. Dit betreft vooral de gesloten 